\title{
El ideario martiano en los textos de La Edad de Oro editada como suplemento al Repertorio Americano y su proyección en
la educación pública costarricense
}

Nuria Rodríguez Vargas Instituto de Estudios Latinoamericanos Universidad Nacional, Costa Rica

Donde hay niños, existe la Edad de Oro. José Martí

\begin{abstract}
Resumen
El presente artículo hace una descripción y explicación general del proyecto de investigación y extensión en el que se estudia y analiza el ideario martiano en la publicación homónima de La Edad de Oro que realizó Joaquín García Monge a través de Repertorio Americano. Su rescate por medio de una publicación digital de los seis tomos y su difusión en el sistema educativo costarricense público a partir de talleres y cursos a estudiantes y docentes de primaria, lleva un análisis de los textos con una lectura desde la literatura infantil, el modernismo y la pedagogía crítica, rescatando así la visión latinoamericanista, pero de carácter universal.
\end{abstract}

Palabras claves: La Edad de Oro, Repertorio Americano, ideario martiano, modernismo martiano, pedagogía crítica, literatura infantil 


\begin{abstract}
This paper presents a description and a general exposition of the extension and research project aiming to study and to analyze the ideas of Martí in his publication La Edad de Oro, by Joaquín García Monge through the Repertorio Americano magazine; its physical conservation in a digital publication in six volumes, and its distribution in the Costa Rican public education system, through workshops and courses for primary teachers allow the analysis of the texts from the point of view of children literature, modernism and critical pedagogy, which offer a Latinamericanist view, but universal in character.
\end{abstract}

Keywords: La Edad de Oro, Repertorio Americano, Martí's ideas, Martí's modernism, critical pedagogy, children literature

\section{Introducción}

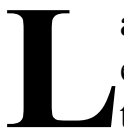
as visitas de José Martí a Costa Rica en 1893 y 1894 son claves para entender el impacto y la influencia que tuvo en grandes intelectuales costarricenses de esos años y los posteriores. "Martí dejó huella imborrable en el alma de los jóvenes", señaló Joaquín García Monge (García Monge, 1942) quien se convertiría en uno de los grandes martianos del continente. En este artículo se explicará y detallará en qué consiste el proyecto de investigación sobre el ideario martiano en la La Edad de Oro de Joaquín García Monge editada como Suplemento al Repertorio Americano. Es una oportunidad para señalar los cruces e influencias martianas que marcaron la vida, producción intelectual, artística y el pensamiento del costarricense en la recopilación de La Edad de Oro.

El proyecto tiene dos ámbitos de acción: por un lado, la investigación sobre la influencia de La Edad de Oro de José Martí (y el ideario martiano presente en esa obra) en la publicación homónima que realizó Joaquín García Monge a través de la revista Repertorio Americano. Y por otro lado, interesa rescatar La Edad de Oro de
García Monge por medio de una publicación digital de los seis tomos, y proyectar su valor cultural y su vigencia educativa a los estudiantes y docentes que laboran en el sistema de Educación General Básica.

A partir de la investigación, localización, lectura, revisión y análisis de los textos publicados en el Repertorio Americano, bajo el título La Edad de Oro, el Rincón de los niños, desde 1924 hasta 1930, se determinará el grado de influencia de $L a$ Edad de Oro de José Martí en la de García Monge, en cuanto a selección de temas, autores y su actualidad.

Se hará la lectura de acuerdo con las particularidades discursivas, textuales y lingüísticas de los textos literarios y no literarios. Con respecto a los textos literarios, se tomarán en cuenta para analizar tres condiciones de la literatura infantil: el aspecto psicológico, el estético y el pedagógico. Así, tanto en la forma como en el fondo, se explicarán aspectos relacionados con la estética modernista, con una mirada desde la perspectiva latinoamericanista y de concientización sobre las principales problemáticas socioculturales, políticas y económicas de la región, pero dentro de un marco universal. 
En tono con lo anterior, se han planteado algunas interrogantes: ¿Cuál ha sido el aporte literario y pedagógico de Joaquín García Monge desde su vigencia en el pensamiento latinoamericano? ¿Cómo influyó Joaquín García Monge por medio de La Edad de Oro en el aporte latinoamericano desde el modernismo, la pedagogía crítica y la literatura infantil? ¿Cuáles ideales martianos trató de difundir García Monge en el sistema educativo costarricense mediante la literatura latinoamericana y universal?

\section{Joaquín García Monge y La Edad de Oro}

La revista Repertorio Americano, dirigida por Joaquín García Monge a lo largo de 39 años, fue la revista hispanoamericana más trascendental de la primera mitad del siglo XX. Gozaba de una excelente reputación en los círculos de intelectuales del continente americano y de Europa, ya que la consumían y escribían en sus páginas. Así, la revista fue una ventana para muchos escritores, pensadores, ensayistas, artistas e intelectuales de varias geografías; además, dio cuenta de los acontecimientos políticos, sociales y económicos de las casi cuatro décadas en que circuló.

Como es bien sabido, García Monge tuvo una gran participación en la difusión de la obra y pensamiento martiano en el sistema educativo costarricense. La publicación en 1914 de una selección de Versos sencillos, de Versos libres y del Ismaelillo marca el inicio de la distribución de la producción del escritor cubano. Además, la Escuela Normal de Costa Rica, formadora de educadores, sería "el espacio más propicio para la divulgación y apropiación de las ideas martianas. Varios de sus directores fueron alentadores del ideario martiano" (Oliva, 1995:73).

Educador entregado, García Monge siempre tuvo una sincera preocupación por la niñez y juventud de su país. Durante su labor como docente se distinguió por inculcar en sus alumnos ideas progresistas. Su visión martiana de la nueva concepción de la literatura para niños lo llevó a fundar la primera cátedra en este campo y a la edición de La Edad de Oro de José Martí en 1921, como se mencionó anteriormente, primera edición en América. Apunta el estudioso martiano Mario Oliva que "a los pocos días de su publicación la obra circulaba entre maestros y niños, sus depositarios naturales. Del Instituto de Alajuela la maestra Adela Salazar reportaba su lectura entre los niños de primer año" (1995: 79).

Por otra parte, García Monge fue más allá y el 16 de junio de 1924 comenzó a publicar en Repertorio Americano, lecturas para niños bajo el nombre La Edad de Oro en honor a la obra original de José Martí. Hizo 77 entradas numeradas hasta el 15 de diciembre de 1924. Hubo una pausa en cuanto a las publicaciones para niños, y el 18 de mayo de 1925 volvió a incluir textos destinados a los pequeños, con el título $L a$ Edad de Oro, Lectura para niños, Suplemento al Repertorio.

Cabe destacar que en marzo de 1925 había anunciado la publicación de La Edad de Oro, como Suplemento al Repertorio Americano y en cuadernos separados de 160 páginas, en total 6 tomos. "Hoy damos a nuestros lectores el número 1 de Tomo I. Póngala en manos de sus hijos o 
discípulos, si los tiene. La Edad de Oro es hija de la entrañable devoción que profesamos a la memoria de José Martí, americano insuperable y ejemplar, en su vida y obra. Don Víctor M. Solano, en la Escuela Juan Rafael Mora de esta ciudad, atiende solicitudes de ejemplares para los niños de las escuelas y colegios" (Repertorio Americano, tomo 10, núm. 5, 1925).

Es notoria la gran recepción de la producción nacional de influencia martiana y el gran esfuerzo llevado a cabo por García Monge por abrir dentro de Repertorio Americano, un pequeño espacio destinado a los niños, además de la publicación y distribución del Suplemento de La Edad de Oro. En total, se hacen 125 entradas en Repertorio Americano, a partir de la publicación del Suplemento de lectura en 1925. Más las 77 entradas de los números anteriores, para un total de 202 entradas en la revista.

Dentro de estos espacios publicó, el maestro García Monge, textos de diversa índole: literarios, históricos, científicos, políticos, entre muchos temas. Autores de muchas geografías, entre los cuales destacaban muchos y grandes latinoamericanos como: Ricardo Palma, Juana de Ibarbourou, Gabriela Mistral, Horacio Quiroga, Amado Nervo, Carmen Lyra, José Martí, solo para citar a algunos. Incluye también a los grandes clásicos como Herodoto, científicos como Charles Darwin, o poemas de Walt Whitman. Es decir, incluyó el maestro García Monge textos literarios y no literarios, lo cual devela los principios martianos de universalidad y formación humanística integral desde las ciencias, las artes y las humanidades.
El pensamiento martiano es una fuente inagotable de conocimiento. En 1992, se crearon oficialmente las Cátedras Martianas en Cuba, que son la mayor fuente de promoción de la vida y obra de Martí en el sector de educación superior y en otros niveles escolares. En la actualidad se han extendido a diferentes universidades de América Latina y a otras geografías continentales. Así, hace más de una década que se celebran en diferentes países de América Latina encuentros de las Cátedras Martianas. Estas constituyen un espacio académico de intercambio, discusión y promoción del pensamiento martiano y su influencia en la historia y cultura nuestramericanas.

La obra e ideario de José Martí continúan siendo actuales y necesarios; su proyecto pedagógico está vigente todavía. Por medio de sus textos literarios, ensayísticos o epistolares arroja rayos de luz para entender y analizar temas que hoy se encuentran en discusión, por ejemplo: la paz, el medio ambiente, la naturaleza, el género, el racismo, la educación inclusiva, la tecnología, los derechos humanos. Nunca es demasiado estudiar al ideólogo cubano. Martí es pensador para todos los tiempos. "(...) Mil hombres pueden escribir, mil veces, sobre un hombre, y su material no se agota, si aquel sobre el cual se escribe ha sido espejo de la vida de millones de hombres; si ha sabido interpretar sus anhelos; si se ha dado por ellos; si se señaló el camino; si su vida fue un anticipo del futuro, marcando la ruta" (García Gallo, 1969:11).

Asimismo, Joaquín García Monge se adentró con fervor en el ideario martiano, lo llevó a su vida y lo difundió pensando 
en las futuras generaciones de Costa Rica y de toda América Latina, "su americanismo es de primer orden por su magnitud, de la que Repertorio Americano es obra sin par expresión de la cultura del continente" (Oliva, 1995:94). Recuerda Luis Ferrero ${ }^{1}$ el pensamiento del educador costarricense: "Martí, con Sarmiento, Bolívar, Hostos, es uno de los seis o siete profetas y conductores de la América hispánica. Seguirlos, atenderlos (que es comprenderlos) es cuestión de tiempo y de cultura mayor: Es su deber, si se quiere crecer".

Así, es de vital importancia recopilar y preservar los seis tomos de La Edad de Oro compilada por García Monge en un libro digital, así como promover su presencia y estudio en diferentes espacios académicos. Además de proyectarla en el sistema educativo costarricense de primaria y secundaria, a partir de actividades de extensión diseñadas para tal propósito, una vez finalizada la etapa de ubicación, clasificación, lectura y análisis de las fuentes.

Como se mencionó anteriormente, García Monge fue pionero en el desarrollo de la literatura infantil en nuestro país, por medio de publicaciones, divulgación de autores nacionales e internacionales, con la instauración de la Cátedra de Literatura Infantil, en 1917, en la Escuela Normal de Heredia, y el establecimiento de un rincón de literatura para niños y niñas en la Biblioteca Nacional, en 1921. Es decir, logró complementar muy bien la parte pedagógica con la literaria; despertar el interés por la lectura mediante textos hermosos en

1 Se encuentra en las notas escritas por Luis Ferrero a la edición costarricense de La Edad de Oro, publicada en coedición por el Centro de Estudios Martianos y la Editorial de la Universidad Estatal a Distancia en 2005. la forma y con fondo interesante que transmitieran aspectos relevantes de la historia y cultura universales.

\section{El Modernismo martiano y la literatura}

El siguiente apartado pretende esbozar de forma general los aspectos teóricos que sustentan la propuesta del presente proyecto. Este se dividirá en la explicación de los conceptos del Modernismo, la Pedagogía Crítica y la Literatura Infantil.

Definir el Modernismo es una tarea compleja y exhaustiva. Desde el siglo XIX hubo divergencia de opiniones. A lo largo de la historia de la crítica literaria se ha definido el Modernismo como "corriente o movimiento literario o artístico"; sin embargo, es más profundo que eso.

Para efectos de este trabajo se manejará la posición de la crítica literaria que sitúa a José Martí como unos de "los precursores" del Modernismo, junto a Manuel Gutiérrez Nájera, José Asunción Silva y Julián del Casal, pues afirman que estos cuatro artistas hicieron sentir nuevas palpitaciones y abrieron el camino a Darío. Por ejemplo: ya Martí había escrito Ismaelillo, Versos Libres, Versos sencillos; Casal con Hojas al viento y Nieve (Oviedo, 2001: 220-222). En esta línea teórica se encuentran estudiosos como Iván A. Schulman, Juan Marinello, Federico de Onís, Manuel Pedro González, B. Gicovate, etc. (Rodríguez, 2005: 173).

El Modernismo hispanoamericano se nutrió de movimientos artísticos de otras geografías. José Miguel Oviedo (2001: 
218) afirma que no hay un Modernismo, hay una pluralidad de modernismos, de un autor a otro, de región a región y dentro de un mismo individuo. Y prefiere los calificativos de reacción, cambio, expresión. Reacción contra los modelos ya fatigados, el academicismo y la expresión literaria conformista y opaca. Además, fue un cambio espiritual que tocó todos los aspectos de la vida hispanoamericana e hispana que afectó todas las artes. En realidad, es expresión de una profunda crisis.

Explica Iván A. Schulman el concepto desarrollado por Federico de Onís en 1934, según el cual el Modernismo "es la forma hispánica de la crisis universal de las letras y del espíritu que inicia hacia 1885 la disolución del siglo XIX y que se había de manifestar en el arte, la ciencia, la religión, la política y gradualmente en los aspectos de la vida entera, con todos los caracteres, por lo tanto, de un hondo cambio histórico "cuyo proceso continúa hoy”. Y continúa diciendo que idéntica concepción es desarrollada por Juan Ramón Jiménez, para quien el Modernismo no fue "solamente una tendencia literaria..." sino "una tendencia general"... [una] cosa de escuela ni de forma, sino de actitud. El encuentro de lo nuevo con la belleza sepultada durante el siglo XIX por un tono general de la burguesía. Eso es el Modernismo: un gran movimiento de entusiasmo y libertad hacia la belleza" (Schulman, 1987:13).

No debe restringirse el Modernismo a un esquema, a una estructura monolítica, a un movimiento artístico de temas exóticos. Se trata de un estilo de época; es más bien rebeldía frente a formas expresivas de los académicos de la época y es sincretismo también, de diversos elementos de la cultura hispanoamericana, de la confluencia de diversos movimientos artísticos del siglo XIX en Europa, además de situaciones ideológicas y filosóficas que marcaron la época (Schulman, 2000:247).

Así pues, José Martí era un modernista que apelaba a una forma de ser, pensar y sentir, a una forma de ver el mundo, por medio de la belleza de la palabra, de las formas y del léxico. Tanto en la prosa como en el verso dominaba recursos estéticos, poéticos y retóricos. La abundancia de epítetos, las figuras literarias y de construcción, los símbolos, la ambigüedad, entre muchos recursos expresivos, contribuían a la expresión de sentimientos plasmada en sus poemas. Sin embargo, no creía en la retórica vacua y vacía. Por encima de todo, estaba el amor a la naturaleza y a lo natural, el mundo de los valores, la ética, la sinceridad, la verdad, la liberación, la entrega, la amistad, la libertad de cada ser humano, de Cuba y de América.

Roberto Fernández Retamar recuerda que Martí puso en tela de juicio la existencia misma de la literatura, en plenitud, allí donde no existe otra plenitud: la histórica. "No hay letras que son expresión", dijo, "hasta que no hay esencia que expresar en ellas. Ni habrá literatura hispanoamericana, hasta que no haya Hispanoamérica". Y señala que "Martí no solo se adelanta con la orquestación magnífica de su prosa o la intensidad de su poesía, sino con los temas que aborda: y tanto en unas como en otros, hallará seguidores dentro del Modernismo" (Retamar, 1978: 79-81). 
Se cuestiona Yerco Moretic, ¿cuál es entonces la característica esencial del aporte formal del Modernismo? Está relacionada con la idea de volverse el poeta hacia las fuentes primigenias: el retorno de la valorización y afinamiento de los sentidos, que permiten al ser humano objetivar la realidad y, al hacerlo, multiplicar la potencia sensorial. El lenguaje modernista es altamente sensitivo. Como dijo Marx, "no sólo es con el pensamiento, sino mediante todos los sentidos, que

el hombre se afirma en

el mundo objetivo."

La prueba de que

las conquistas

modernistas no

se limitan a

los regodeos

formalistas,

huérfanos

de sustancia vital, está en el hecho de que si se intentara suprimir la poesía modernista, no se podría comprender la poesía posterior, incluida la de hoy (Moretic, 1986: 59-60).

En síntesis, el modernismo martiano en cuanto a la forma y al fondo en la literatura, se caracterizó por las renovaciones técnicas y léxicas dentro de un lenguaje sensitivo y un rescate de la lengua castellana, pues lo hispánico se impuso en lo lingüístico y lo estilístico como norma expresiva. Sin embargo, hubo asimilación de las literaturas extranjeras en construcciones hispánicas, pues se planteaba una estética sincrética que uniera lo local con lo universal, para procurar una literatura con preocupaciones ideológicas y filosóficas, y que hubiera una vital relación entre arte, existencia y cultura.

Dentro de este marco artístico e histórico se publicó La Edad de Oro en 1889. “(...) un libro que funda un tipo de literatura y un modelo pedagógico para nuestros pueblos, que no ha perdido su vigencia". En su época, fue un libro de ruptura, se opuso la literatura martiana para niños a las concepciones tradicionales en esa época. El escritor mexicano y poeta Manuel Gutiérrez Nájera "comprendió muy bien la capacidad de Martí para ponerse al nivel del niño sin desmedro de la profundidad de los contenidos" (Escobar Valenzuela, 1990: 32-34).

Se mencionó anteriormente el concepto "literatura para niños". Queda claro que fue Martí el iniciador, el pionero en nuestro continente de un tipo diferente e innovador de literatura dirigida a los pequeños. En las líneas siguientes, se sintetizarán algunos aspectos en la historia de ese tema en Latinoamérica y, por extensión, en Costa Rica. 
La literatura infantil en América Latina se remonta a las tradiciones orales precolombinas, las canciones de cuna, mitos, leyendas, retahílas, rondas, coplas, adivinanzas, trabalenguas, villancicos y rimas. Todos estos elementos contienen las más diversas raíces: indígenas, europeas, africanas y orientales. El resultado final de la fusión es el origen de la literatura infantil latinoamericana. Es hasta el siglo XIX que las imprentas de América Latina tienen como destinatarios a los niños. Sin embargo, las primeras ediciones estaban destinadas al aprendizaje de la lectura y catecismos.

Un siglo antes, en Europa, estas ideas habían detenido el desarrollo de la buena literatura infantil y en nuestras tierras se cayó en el mismo error. "Lo usual en las lecturas que se difunden en estas décadas, es el tono docto y admonitorio, el afán moralizante a ultranza. El premio a la virtud, el temor irracional a Dios y el castigo a la desobediencia" (Rodríguez, 1993:14).

A pesar de la situación anterior, destacó en ese período el cubano José Martí quien, en 1889, publicó la revista para niños $L a$ Edad de Oro, en la que intentó educar a la niñez latinoamericana en el amor por sus propias raíces americanas y el reconocimiento de nuestra cultura mestiza, de una manera lúdica a partir del ingenio, la metáfora y la narración. En ella puso su empeño por crear en los niños de América Latina, amenazados por lo que él llamaba la pérdida continua de la identidad, una conciencia anticolonialista, una escala de valores y ofrecerles, además, literatura. "Su originalidad radica, sobre todo, en la disposición para hallar el conocimiento profundo en lo autóctono- sin renunciar a los aportes externos- las fuerzas, las ideas y las soluciones a nuestros problemas. La mirada martiana se extendió por un amplio espectro de temas de carácter nacional, continental y universal" (Poey Baró, 1999: 74).

De esa revista se publicaron cuatro números, en los meses de julio, agosto, septiembre y octubre de 1889. "La Edad de Oro fue el noble modelo que constituyó por sí solo en nuestros países el nacimiento y el fin, en su época, de una tendencia ejemplar de la revista para niños; tras su paso efímero, nacieron y medraron tendencias de otro signo, que conquistaron el triunfo por asalto con inesperado vigor" (Almendros, 1985:14). Las razones por las que se dejó de editar la revista obedecieron a la negativa de Martí a someterla a una moral dogmática y puritana, en vez de transmitir los valores éticos fundamentales del ser humano como tolerancia, solidaridad e integración.

En el caso del desarrollo de la literatura infantil en Costa Rica, su arranque está marcado por la fundación de la Escuela Normal en 1914 y por el gran impulso de Joaquín García Monge en la revista $R e$ pertorio Americano. Apunta Mario Oliva que en Martí hay una visión nueva de lo que debe ser la literatura infantil. "Carmen Lyra y Joaquín García Monge son pioneros en nuestro país (...) Don Joaquín ha fundado la primera cátedra de literatura para niños, que considera esencial en la preparación de los maestros de la Escuela Normal de Costa Rica (...) divulgaba además de la obra de Martí a Fernán Caballero, Juan Ramón Jiménez, Rafael Pombo (...) entre muchos otros" (Oliva, 1995:74). 
En el nivel continental, en los primeros años del siglo XX existía una preocupación por la literatura para niños, tanto de escritores que escriben especialmente para ellos, como otros ya consolidados en la literatura para adultos, por ejemplo: José Martí, Rubén Darío, Horacio Quiroga, Amado Nervo, Juana de Ibarbourou y Jorge Amado. Estos escritores y muchos otros, que son parte del canon literario, aparecieron durante años en las publicaciones de la revista Repertorio Americano y fueron incluidos en la selección hecha por Joaquín García Monge, La Edad de Oro como Suplemento al Repertorio.

La difusión de estos escritores y sus obras fue significativa pues tuvieron una buena recepción por parte del público latinoamericano de las diferentes décadas del siglo $\mathrm{XX}$. "Solo en el plano reflexivo de la experiencia estética, el observador saboreará o sabrá saborear estéticamente situaciones de la vida que reconoce en ese instante o que le afectan personalmente, siempre que, de manera consciente, se introduzca en el papel del observador y sepa disfrutarlo" (Jauss, 1986: 17).

\section{El aporte pedagógico martiano y su vigencia}

Por otro lado, un tema que no puede dejarse de lado cuando se habla de La Edad de Oro es la parte pedagógica. En la introducción de La Edad de Oro se evidencia su ideario pedagógico y su concepto de educación “(...) para que los niños americanos sepan cómo se vivía antes, y se vive hoy, en América, y en las demás tierras; y cómo se hacen tantas cosas de cristal y de hierro, y las máquinas de vapor, y los puentes colgantes (...) donde suceden cosas más raras e interesantes que en los cuentos de magia (...) lo que se sabe del cielo, y de lo hondo del mar y de la tierra (...) (Martí, 1889:17). Se observa la idea de una educación integradora de las Ciencias y las Humanidades. "Sus conceptos sobre educación aún hoy día resultan novedosos $\mathrm{y}$, tememos a veces, poco atendidos" (Arias, 2012:52).

Felipe Pérez Cruz (2011: 230) afirma que el proyecto educativo cultural de José Martí conforma un sistema de principios, valores, concepciones metodológicas, ideas y acciones encaminados a una formación general integral de los sujetos de la educación, con un elevado sentido ético, filosófico, estético, político, cultural y práctico, síntesis y disparador de una formación cosmovisiva científica humanista, que permita preparar a cada hombre para sentirse ser de la naturaleza, inserto en los retos de su sociedad. De acuerdo con lo anterior, el pensamiento martiano puede resumirse en doce principios pedagógicos rectores: la formación cultural y educativa como acto liberador, carácter ético, democrático, patriótico, científico y popular de la educación; la educación como derecho y deber de todos los ciudadanos, la educación como tarea de masas, la unidad dialéctica de la función instructiva y educativa en el acto y en el proceso docente, la combinación del estudio y el trabajo en las escuelas, la educación laica y la coeducación (Pérez, 2011: 231). Principios todavía vigentes en la solución de problemas específicos de cada país latinoamericano en diferentes momentos históricos. 
Es interesante resaltar el carácter visionario de José Martí, anticipado a su época, pensador para todos los tiempos. En su pensamiento educativo se pueden encontrar principios que se han puesto en práctica en los siglos XX y XXI como los citados anteriormente. Así, en este momento histórico se podría leer el proyecto educativo martiano desde la Pedagogía Crítica, entendida como una práctica pedagógica horizontal, donde se construye el conocimiento de forma crítica a través de una lectura compleja de la realidad y que tiene como objetivo la transformación social y la libertad del individuo. Así, en palabras de Martí, “educar es depositar en cada hombre toda la obra humana que le ha antecedido; es hacer a cada hombre resumen del mundo viviente, hasta el día en que vive; es ponerlo a nivel de su tiempo, para que flote sobre él, y no dejarlo debajo de su tiempo, con lo que no podrá salir a flote; es preparar al hombre para la vida" (Martí, 1953-1895/2001e: 281).

Para efectos del presente trabajo, interesa centrarse en varios temas que se desprenden de los principios, por ejemplo, la educación e igualdad de oportunidades y la educación para todos, es decir que todos tengan la posibilidad de crecer, personas con necesidades especiales y los adultos mayores, además del desarrollo de la educación no formal. Esto último ligado al concepto de educación permanente “(...) la educación empieza con la vida, y no acaba sino con la muerte. El cuerpo es siempre el mismo y decae con la edad; la mente cambia sin cesar, y se enriquece y perfecciona con los años (...) Lo general es que el hombre no logre en la vida un bienestar permanente sino después de muchos años de esperar con paciencia y de ser bueno, sin cansarse nunca" (Martí, 1889:57).

Otro de los temas es educación y cambio social, la transformación de la sociedad mediante la lucha y conciencia en temas de género, ambientales y de racismo. Por ejemplo, en La Edad de Oro, "Martí hace una distinción importante. Habla de las niñas y los niños. Las niñas se convierten en principales protagonistas y heroínas de algunos de los cuentos (...) sin las niñas, dice el apóstol, "no se puede vivir como no puede vivir la tierra sin luz". Entre el niño y la niña, entre el hombre y la mujer debe existir una igualdad. Y continúa diciendo Martí que "las niñas deben saber lo mismo que los niños para poder hablar con ellos como amigos cuando vayan creciendo" (Escobar, 1990: 36).

Por otra parte, en el cuento de Martí, "La muñeca negra", se plantea la cuestión de la discriminación racial. Afirma Dionisio Poey Baró que la mirada de Martí, inserta dentro del carácter nacional, continental y universal, se preocupó por la lucha contra el racismo y la discriminación racial. “Aún se conoce muy poco acerca del proceso mediante el cual logró convertirse en uno de los pensadores antirracistas más significativos de la historia, con un ideario vigente en la actualidad (...) pero la forma más segura de cortar la cadena de transmisión era educando consecuentemente a los niños, y para ello desempeñará una cuidadosa labor al respecto en la revista, $L a$ Edad de Oro" (Poey Baró, 1999: 74-75).

La transformación social como una exigencia latinoamericana de la educación es otro de los temas originados de los 
principios filosóficos descritos anteriormente. Martí proponía una educación emancipadora, para obtener el progreso social, el desarrollo y la libertad. Ligado se encuentra también el tópico del sujeto del proceso educativo; es decir, donde el docente y el alumno sean sujetos activos, el proceso educativo esté acorde con las necesidades de la época y haya una formación integral y multicultural mediatizada por valores como solidaridad, equidad y tolerancia.

Los temas anteriores son una constante en el pensamiento martiano, y recalca Salvador Arias su presencia en La Edad de Oro, en el caso de América Latina, la cuestión del indígena es un aspecto clave en el desarrollo del continente, "pero al cual ningún estudioso martiano podrá referirse sin adentrarse en los artículos "Las ruinas indias" y "El padre las Casas", a quien "con la bondad se le fue poniendo de lirio el color" (Arias, 2005:50).

Parafraseando a Gustavo Escobar Valenzuela (1990: 38-39), una de las constantes en La Edad de Oro es una visión horizontal que Martí tiene de los seres humanos y los pueblos. No hay razas ni pueblos superiores. Es una obra que propone derribar mitos, prejuicios, combatir ignorancias y fanatismos. "También Martí conoce el poder de las tinieblas, y sabe que ninguna es más perniciosa y proclive a despertar visiones engañosas que aquella que provoca la tergiversación de la historia de la tierra en que se nace. Si esta no se conoce acertadamente, no habrá después posibilidad de corregir el rumbo del pensamiento y de las emociones (...)" (Gallego Alonso, 1989: 65-66).
La capacidad de anticipación del pensamiento martiano es sorprendente. Cristina Miranda Espinosa (1999: 117) sostiene que La Edad de Oro fue el primer intento de lo que hoy llamamos Educación a Distancia en Cuba y América cuando apenas esa modalidad era conocida en el mundo. $\mathrm{Y}$ asegura que la revista contiene elementos que caracterizan esta modalidad educativa, "constituye un manual en el cual los niños y jóvenes de ayer y hoy, pueden adquirir conocimientos e incorporar a la vida valores como: la honradez, la sencillez, la solidaridad, el amor a la gran patria americana, a sus mártires, el amor a la naturaleza, en fin a todo el universo" (Espinosa, 1999:118). Y concluye que podría decirse que la revista fue un "texto virtual" en el siglo XIX, ligado a la idea de la educación permanente y a distancia.

\section{Literatura infantil y juvenil para la instrucción y el goce}

En la segunda mitad del siglo XX se da todo un debate con respecto a la definición de literatura infantil, o bien literatura para niños y niñas, un concepto que ha sido complicado y polémico, pues mucho se ha escrito sobre el término y las características que debe tener un libro escrito para niños. Se podrían citar algunas definiciones al respecto. "La literatura infantil es un acto de comunicación, de carácter estético, entre un receptor niño y un emisor adulto que tiene como objetivo sensibilizar al primero y como medio la capacidad creadora y lúdica del lenguaje y debe responder a las exigencias y necesidades de los lectores" (Perriconi, 1983:6). 
El término "infantil pesa, pesa mucho y, para algunos, mucho más que la literatura. Es natural, no puede dejar de pesar: una literatura fundada en una situación comunicativa tan despareja -el discurso que un adulto le dirige a un niño, lo que alguien que "ya creció" y "sabe más" le dice a alguien que "está creciendo" y "sabe menos"- no puede dejar de ser sensible a este desnivel. Es una disparidad que tiene que dejar huellas..." (Montes, 2001:18).

O bien, una definición más amplia que explica que literatura infantil es aquella en la que "se integran todas las manifestaciones y actividades que tienen como base la palabra con finalidad artística o lúdica que interesan al niño" (Cervera, 1991:11). Para efectos de este trabajo, no se entrará en la discusión teórica entre los términos literatura infantil y literatura juvenil, sino que se tratará como un solo concepto, la literatura infantil y juvenil.

Parafraseando a la investigadora costarricense Magdalena Vásquez Vargas, ella explica que todas las clasificaciones son limitadas, porque producen una imagen, aunque no equivocada, sí parcial. En el caso de la literatura infantil y juvenil, estas se han clasificado considerando la población a la que van dirigidas. Por eso, al analizar las obras literarias infantiles y juveniles el crítico no debe olvidarse de que se está enfrentando ante todo a la literatura (2002: 122-123).

A pesar de las múltiples definiciones y debates, la literatura infantil debe ser valorada desde su pertenencia a la literatura general, no deberían oponerse una y otra. Ni se le debería poner un apellido.
Hacer tantas clasificaciones de esta podría resultar complicado y peligroso para las posibilidades de interpretación. El arte es general. "Existe un arte de tal sencillez y pureza emocional, que el olfato infantil goza...porque es arte" (Montes, 1999: 83).

Sin embargo, la literatura infantil tiene características específicas que no se pueden pasar por alto, por lo tanto es necesario relacionarlas y complementarlas. Margarita Dobles cita a Fabián Dobles, quien teorizando sobre la literatura infantil, escribió en Repertorio Americano: "Fantasioso y dramático, animista y prodigioso como es lo infantil, la literatura para niños es fantasía, prodigio y animación, vivificación de lo animado (...) No es por casualidad que el artista y el niño se parecen tanto. Unos y otros usan un lenguaje especial, distinto al de los demás hombres (Dobles, 2003:9).

Alga Marina Elizagaray (1975) da una lista de características que debe tener todo libro para niños: formativo, realista pero poético, tierno y fantasioso, sencillo y poseer mucho diálogo y acción. Así, el libro infantil tiene diversas funciones, pero la principal es formar y habituar a los niños a la lectura. Elizagaray cita a Goethe, "tenemos que librarnos de buscar lo que educa exclusivamente en lo moral. Todo lo grandioso educa, con tal que nos demos cuenta de ello." Y expone con sus propias palabras, en referencia al libro para niños, "Por tanto debe informar y formar, o sea contribuir a sensibilizar el mundo interior del niño y condicionarlo como lector. Cuando echamos una ojeada a la infancia de los grandes hombres, vemos que en ella ha habido muchos libros y buenos" (1975:8). 
De acuerdo con lo anterior, escribir para niños no se diferencia de hacerlo para adultos, implica la misma responsabilidad y búsqueda de la calidad. Debe formar a los niños y jóvenes pero desde el disfrute y el gusto por la lectura. Muchas de las grandes obras de la literatura universal, como Alicia en el país de las maravillas de Lewis Caroll o El Principito de Antoine de Saint Exupéry, solo para citar dos ejemplos, no fueron escritas para un público infantil y no tenían como objetivo la construcción de aprendizajes, aunque sí la formación de hombres y mujeres críticos.

Concluye la investigadora Nuria Méndez: "la literatura para niñas y niños es un fenómeno social amplio. Su crítica literaria está en construcción (...) se seleccionan y le aplican instrumentos de análisis como resultado de otras disciplinas. Se desprende lo pedagógico y se consolida como literatura, no como un género menor- como antes se le había llamado" (2009:6).

Por otra parte, para efectos del presente proyecto, es importante destacar que los talleres de lectura crítica se realizarán con niños, niñas y jóvenes en edad escolar, desde 7 años hasta 14 años. Con base en aportes de Piaget y Freud, se ha divido en tres etapas: la edad de las hadas, entre los 7 y 9 años, la etapa de la realidad-fantasía, entre 9 y 12 años y finalmente el estadio de las operaciones abstractas, la adolescencia. "Para Piaget el pensamiento del niño de esta edad se encuentra a medio camino entre el pensamiento adulto socializado y el pensamiento artístico y egocéntrico del pensamiento freudiano" (Flavell, 1993: 173-174).
Como se había mencionado anteriormente, "América Latina es sinónimo de mestizaje, lo que hace posible que en nuestra literatura infantil se descubran aportes de diferentes culturas, en un horizonte donde conviven préstamos del sustrato indígena, fuentes de la tradición oral africana, herencias de la conquista española y una literatura vernácula que sostiene su personalidad en una permanente búsqueda (...) América Latina no es un conjunto homogéneo, sino múltiple y complejo" (Hanán Díaz, 2011).

En síntesis, el proyecto amarra las tres categorías teóricas citadas al principio: el modernismo martiano, la pedagogía crítica y la literatura infantil, para así destacar los aportes formales e ideológicos del Modernismo, en relación con temas desprendidos de los principios pedagógicos $\mathrm{y}$ literarios que dieron forma al proyecto martiano dirigido a los niños y niñas de América. La literatura infantil, no como una "herramienta" para enseñar la lengua española, sino como fuente de placer, goce y de instrucción sobre la historia, pensamiento y cultura latinoamericanos.

\section{A modo de conclusión}

Finalmente, nunca está de más destacar la gran labor de difusión de la cultura, historia y pensamiento latinoamericano llevada a cabo por Joaquín García Monge a lo largo de casi cuarenta años en la revista Repertorio Americano. En el caso particular de La Edad de Oro, es importante proyectar para no condenar al olvido tan significativo aporte a la educación costarricense. Es necesario que las nuevas generaciones conozcan y se identifiquen con 
pensamientos, ideas, valores de raíz latinoamericana y de carácter universal.

Los textos y autores seleccionados por Joaquín García Monge e incluidos en $\mathrm{La}$ Edad de Oro marcaron época; sin embargo, por tratarse de temáticas latinoamericanas y universales trascienden el tiempo y son aplicables a cualquier contexto educativo. Es un material valioso, por lo que son imperativas su sistematización, publicación y difusión.

Por otra parte, el contacto con los docentes de primaria y los estudiantes del sistema educativo público, por medio de talleres y cursos, es fundamental para el intercambio de saberes y la transformación social, uno de los principios fundamentales del ideario martiano que ha sido retomado y desarrollado por la Pedagogía Crítica. Por otra parte, se potencia el desarrollo de habilidades, aptitudes y destrezas individuales, así como el trabajo en equipo mediante la organización de actividades, discusión, reflexión, creatividad y criticidad.

Se cumple uno de los principios por los que fue creada la Universidad Nacional: el acercamiento a la comunidad y el compromiso con los diversos sectores y actores sociales. Así, los ciudadanos, en este caso los educadores y estudiantes, son los protagonistas de la democratización del saber.

\section{Bibliografía}

Arias, S. (2005). "La literatura: vehículo eficaz para la comunicación martiana con niños y jóvenes. En: Anuario del Centro de Estudios Martianos, no. 28 . . (2012). Un proyecto martiano esencial: La Edad de Oro. La Habana: Centro de Estudios Martianos.

Cervera, J. (1991). Teoría de la literatura infantil. Bilbao: Mensajero.

Dobles, M. (2003). Literatura infantil. San José: Editorial de la Universidad Estatal a Distancia.

Elizagaray, A. (1975). En torno a la literatura infantil. La Habana: Unión de Escritores y artistas de Cuba.

Escobar Valenzuela, G. (1990). "Reflexiones sobre la Edad de Oro, de José Martí. En: Anuario del Centro de Estudios Martianos, $\mathrm{N}^{\circ} 13$.

Flavell, J. (1993). La psicología evolutiva de Jean Piaget. México: Paidós.

García Gallo, G. (1969). Martí, americano y universal. La Habana: Instituto Cubano del Libro.

García Fallas, J. "El proyecto educativo de José Martí: una lectura desde la pedagogía crítica". En: Revista de Educación, 28, 1.

García Monge, J. (1921). La Edad de Oro de José Martí. San José: El Convivio de los Niños.

. Repertorio Americano, tomo 10, No $5,1925$.

. Repertorio Americano. Semanario de Cultura Hispánica de Filosofía y Letras, Artes, Ciencias y Educación, Misceláneas y Documentos. Tomos del 8 al 20, años 1924-1930. 
Hanán Díaz, F. (2011). "Literatura infantil latinoamericana”. En: http://www. dondevivenloslibros.com/2011/08/ literatura-infantil-latinoamericana. html Descardado el 9 de mayo de 2016.

Jauss, H. (1986). Experiencia Estética y Hermenéutica Literaria. Madrid: Taurus.

Martí, J. (2005). La Edad de Oro. San José: Editorial de la Universidad Estatal a Distancia.

Méndez Garita, N. (2009). Literatura para niñas y niños: de la didáctica a la fantasía. Colección Pedagógica Formación Inicial de Docentes Centroamericanos de Educación Primaria o Básica. San José: Coordinación Educativa Cultural CentroamericMiranda Espinosa, M. (1999). "La Edad de Oro, ¿texto virtual en el siglo XIX?". En: Anuario del Centro de Estudios Martianos, $\mathrm{N}^{\mathrm{o}} 22$.

Montes, G. (1999). La frontera indómita. En torno a la construcción y defensa del espacio poético. México: Fondo de Cultura Económica. . (2001). El corral de la infancia. Nueva edición, revisada y aumentada. México: Fondo de Cultura Económica.

Moretic, Y. (1986). Acerca de las raíces ideológicas del modernismo hispanoamericano en Lily Litvak, El Modernismo. Madrid: Editorial Taurus.

Oliva, M. (1995). José Martí en la historia y la cultura costarricense. Heredia: Editorial de la Universidad Nacional.
Oviedo, J. (2001). Historia de la literatura hispanoamericana 2. Del Romanticismo al Modernismo. Madrid: Alianza Editorial.

Poey Baró, D. 1999). "Para un futuro sin prejuicios: La Edad de Oro". En: Anuario del Centro de Estudios Martianos, № 22.

Perriconi, G. (1983). El libro infantil. Cuatro propuestas críticas. Buenos Aires: El Ateneo.

Pérez Cruz, F. (2011). "Raíces históricas del proyecto educativo martiano". En: Revista de la Historia de la Educación Latinoamericana, 13,17 , jul-dic.

Retamar Fernández, R. (1978). Introducción a José Martí. La Habana: Casa de las Américas.

Rodríguez, O. (1993). Literatura infantil en América Latina. San José: UNESCO.

Rodríguez, J. y Salvador, A. (2005). Introducción al estudio de la literatura hispanoamericana $3^{a}$ ed. Madrid: Ediciones Akal.

Schulman, I. (1987). "Modernismo- Modernidad: metamorfosis de un concepto". En Nuevos asedios al Modernismo. Madrid: Editorial Taurus. . (2000). El proyecto inconcluso: la vigencia del Modernismo. México: Siglo XXI.

Vásquez Vargas, M. (2002). "Fundamentos teóricos para una interpretación crítica de la literatura infantil". En: Revista Comunicación, 12, 2, julio-diciembre. 